\title{
Spherical Surface Vibration Identification by Spherical Holography and Acoustic Intensity
}

Jen-Chieh Lee

Associate Professor, Department of Marine Engineering and Technology, National Taiwan Ocean University, Keelung, Taiwan, R.O.C.

Follow this and additional works at: https://jmstt.ntou.edu.tw/journal

Part of the Engineering Commons

\section{Recommended Citation}

Lee, Jen-Chieh (1996) "Spherical Surface Vibration Identification by Spherical Holography and Acoustic Intensity," Journal of Marine Science and Technology. Vol. 4: Iss. 1, Article 11.

DOI: $10.51400 / 2709-6998.2544$

Available at: https://jmstt.ntou.edu.tw/journal/vol4/iss1/11

This Research Article is brought to you for free and open access by Journal of Marine Science and Technology. It has been accepted for inclusion in Journal of Marine Science and Technology by an authorized editor of Journal of Marine Science and Technology. 


\title{
SPHERICAL SURFACE VIBRATION IDENTIFICATION BY SPHERICAL HOLOGRAPHY AND ACOUSTIC INTENSITY
}

\author{
Jen-Chieh Lee*
}

Keywords: Identification, Spherical Holography, Acoustic Intensity.

\section{ABSTRACT}

This study presents the capabilities of spherical surface vibration identification by using spherical acoustical holography and acoustic intensity measurement. The spherical holographic technique reconstructs the surface particle velocity from the acoustic pressure on the hologram. The acoustic pressure can be calculated from acoustic intensity measurement. The results of computer simulation show that, based on one direction acoustic intensity measurement only, spherical surface vibration can be identified from spherical holographic techniques.

\section{INTRODUCTION}

To reduce machinery noise, it is important first to gain some knowledge about the noise sources and sound fields produced by sound sources. Acoustic field data in the near vicinity of a vibrating structure can be used to evaluate either the acoustic farfield or the source characteristics. The prediction of acoustic farfield from near data is but a special case of the forward holography of acoustic fields. Alternately, the identification of sources characteristics for a vibrating structure is a special case of the backward holography of acoustic fields.

Acoustic holography for the purpose of noise source identification has most often been applied in planar geometry. However, many small machines have shapes that make planar holography inconvenient. In this case, spherical or cylindrical geometries analysis may yield better results. The spherical holography technique has been applied in cases where the sound source may be entirely enclosed by a sphere on which sound pressure is measured. Lee [1] inves- tigated the performance of nearfield reconstruction at low frequency using the spherical holographic techniques, and the results show that the precise reconstruction of source surface pressure and particle velocity can be obtained with an optimum order number of holographic wave and a small radius hologram pressure data. Devries et al. [2] applied the technique in both simulation and experiment to confirm the acc-racy of spherical holography and identify the noise source for small machines, especially a refrigeration compressor. Zhukov et al. [3] identified the multipole source sound field energy characters in spherical coordinates. Weinreich and Arnold [4] designed an experiment in which a boom system was employed to measure the complex sound pressure on two concentric spheres. They expanded the solution of wave equation in spherical coordinates with the spherical harmonics calculated from the measurements; their method can be used to characterize the sound field when both incoming and outgoing waves are present. Laville et al. [5] developed a spherical acoustical holography technique that uses sound intensity measurements to project the sound field for outgoing waves only.

The holographic techniques for the noise sources identification is a promising direction in aeroacoustics and underwater acoustics. However all holographic techniques require the complex pressure on the hologram surface. To reduce the inconvenience of measuring complex pressure at a large number of receiver, the use of a phase reference signal has been proposed [6]. Nonetheless, this technique remains difficult to apply when a reference signal to represent of the source is not available, or where this signal is not unique for the whole radiated field. To eliminate the need for a reference signal and a large number of receiver array, Loyau [7] develops a method to obtain the complex pressure by processing measurements of active intensity and quadratic pressure. In the past work, for the spherical acoustical holography, only Laville [5] have extended Loyau's approach to forward project the sound field at outgoing waves. 
Therefore this paper extends the previous work [1] to identify the spherical surface vibration by using backward holographic techniques based on the sound intensity measurements, and the results of numerical simulation prove the capabilities of spherical surface vibration identification using the holographic techniques.

\section{RELATIONS OF HOLOGRAM PRESSURE AND ACTIVE INTENSITY}

The acoustic pressure for a monochromatic field is given by

$$
p(M)=|p(M)| e^{j \phi(M)}
$$

where $|P(M)|$ and $\phi(M)$ are real; $M$ is the spatial variable. The particle velocity is found from Euler's equation:

$$
\begin{aligned}
u(M) & =\left(\frac{-1}{j \omega \rho_{0}}\right) \nabla p(M) \\
& =\left(\frac{1}{\omega \rho_{0}}\right)[-|p(M)| \nabla \phi(M) \\
& +j \nabla|p(M)|] e^{j \phi(M)} .
\end{aligned}
$$

The complex acoustic intensity $I_{c}(M)$ is defined as the conjugated product of acoustic pressure and particle velocity:

$$
\begin{aligned}
I_{c}(M) & =\frac{1}{2} p(M) u^{*}(M)=I(M)+j Q(M) \\
& =\frac{1}{2 \omega \rho_{0}}\left[-|p(M)|^{2} \nabla \phi(M)\right. \\
& -j|p(M)| \nabla|p(M)|],
\end{aligned}
$$

where $Q(M)$ is a reactive intensity and the active intensity $I(M)$ is a function of quadratic pressure and phase gradient. To rewrite the active intensity part as

$$
\nabla \phi(M)=-2 \omega \rho_{0} \frac{I(M)}{|p(M)|^{2}} .
$$

This equation is used for the hologram pressure reconstruction from intensity measurements. To use equation (4) in spherical coordinates, all the meridian lines intersect each other at two common points, we need only to consider the $\theta$ component of the active intensity and the gradient $\phi$ :

$$
\frac{1}{r} \frac{\partial \phi(M)}{\partial \theta}=-2 \omega \rho_{0} \frac{I_{\theta}(M)}{|p(M)|^{2}} .
$$

Taking the spatial Fourier transform (F) of equation (5) gives

$$
\begin{aligned}
& \phi_{r, \varphi}\left(k_{\theta}\right)=\frac{\beta_{r, \varphi}\left(k_{\theta}\right)}{j k_{\theta}}, \\
& \beta_{r, \varphi}\left(k_{\theta}\right)=F\left[-2 r \omega \rho_{0} \frac{I_{\theta}(M)}{|p(M)|^{2}}\right] .
\end{aligned}
$$

The phase of the complex pressure on the hologram is obtained by taking the inverse Fourier transform $\left(F^{-1}\right)$ of equation (7):

$$
\phi(M)=F^{-1}\left[\phi_{r, \varphi}\left(k_{\theta}\right)\right] .
$$

The complex pressure is reconstructed from equation (1) after the phase is found from equation (8).

\section{SPHERICAL HOLOGRAPHY THEORY}

The wave equation in spherical coordinates can be solved using Fourier's method of separating the variables. The radial component of the sound field is described by spherical hankel functions, and the ploar and azimuthal components are described by the legendre functions, through which the spherical harmonics can be calculated. We take the acoustic pressure as the primary field quantity and represent the general form as

$$
\begin{aligned}
p(M, \omega) & =\sum_{n=0}^{+\infty} h_{n}(k r) \sum_{m=0}^{n}\left[A_{n m} Y_{n m}^{+}(\theta, \phi)\right. \\
& \left.+B_{n m} Y_{n m}^{-}(\theta, \phi)\right] .
\end{aligned}
$$

Here $p(M, \omega)$ is the complex pressure at frequency $\omega$ and locations $\mathbf{M}$ on any spherical surface. Spherical hankel function $h_{n}(k r)$ can be calculated using a linear combination of the spherical Bessel and Neumann function [8]. The spherical surface harmonics $Y_{n m}^{+}(\theta, \phi)$ and $Y_{n m}^{-}(\theta, \phi)$ are defined by

$$
\begin{aligned}
& Y_{n m}^{+}(\theta, \phi)=\cos (m \phi) \sin ^{m}(\theta) \frac{d^{m} P_{n}(\cos \theta)}{d(\cos (\theta))^{m}} ; \\
& Y_{n m}^{-}(\theta, \phi)=\sin (m \phi) \sin ^{m}(\theta) \frac{d^{m} P_{n}(\cos \theta)}{d(\cos (\theta))^{m}} ;
\end{aligned}
$$

where $\theta$ is the polar angle measured from the position $\mathrm{z}$ axis, and $\phi$ is the azimuthal angle measured from $\mathrm{x}$ axis. $P_{n}(\cos \theta)$ is the $\mathrm{n}$ order legendre function expanded in power of $\cos \theta$. The radial component of acoustic particle velocity can be defined as

and

$$
u_{r}(M, \omega)=\frac{-1}{j \omega \rho_{0}} \frac{\partial p(M, \omega)}{\partial r}
$$

$$
\begin{aligned}
\frac{\partial p(M, \omega)}{\partial r}= & k \sum_{n=0}^{\infty} \frac{d h_{n}(k r)}{d(k r)} \sum_{m=0}^{n}\left[A_{n m} Y_{n m}^{+}(\theta, \phi)\right. \\
& \left.+B_{n m} Y_{n m}^{-}(\theta, \phi)\right] .
\end{aligned}
$$


The radial direction derivative of the hankel function can be expressed in a recursive form:

$$
\frac{d h_{n}(k r)}{d(k r)}=\frac{n}{k r} h_{n}(k r)-h_{n+1}(k r),
$$

Where $\mathrm{k}$ is wave number. The harmonic coefficients $A_{n m}$ and $B_{n m}$ can be derived by using the orthogonality of the spherical harmonics [1]

$$
\begin{aligned}
A_{n m}= & \frac{2 n+1}{4 \pi} \varepsilon_{m} \frac{(n-m) !}{(n+m) !} \\
& \int_{0}^{2 \pi} d \phi \int_{0}^{\pi} p(M, \omega) Y_{n m}^{+}(\theta, \phi) \sin \theta d \theta, \\
B_{n m}= & \frac{2 n+1}{4 \pi} \varepsilon_{m} \frac{(n-m) !}{(n+m) !} \\
& \int_{0}^{2 \pi} d \phi \int_{0}^{\pi} p(M, \omega) Y_{n m}^{-}(\theta, \phi) \sin \theta d \theta .
\end{aligned}
$$

Here $m=0, \varepsilon_{m}=1$ and $m \geq 1, \varepsilon_{m}=2$. Once the harmonic coefficients are found, the pressure and particle velocity fields may be projected away from or toward the source as needed by using the equations (9) to (11).

\section{SPHERICAL SURFACE VIBRATION IDENTIFICATION}

The numerical example considers a piston of radius $a \sin \theta_{0}$ set in the side of a rigid sphere to vibrate its surface. If $\theta_{0}$ is not too large, the spherical surface velocity distribution can be defined as: $U(\theta)=u_{0}, 0 \leq$ $\theta<\theta_{0}$ and $U(\theta)=0, \theta_{0} \leq \theta<\pi$, where a is the radius of sphere. The sphere surface vibrates with a velocity $U(\theta) e^{-j \omega t}$. In term of a series of legendre functions, the velocity amplitude can be expressed as [8]

$$
U(\theta)=\sum_{n=0}^{\infty} U_{n} P_{n}(\cos \theta),
$$

where

$$
U_{n}=\left(n+\frac{1}{2}\right) \int_{0}^{\pi} U(\theta) P_{n}(\cos \theta) \sin \theta d \theta .
$$

Corresponding to velocity $U(\theta) e^{-j \omega}$, the theoretical pressure can be expressed as

$$
p=\sum_{n=0}^{\infty} A_{n} P_{n}(\cos \theta) h_{n}(k r) e^{-j \omega t},
$$

where the values of the coefficient $A_{n}$ must be determined with the known coefficient $n$. Figures 1 to 3 are obtained by using the numerical values, as follows $a=0.2, \theta_{0}=\frac{\pi}{10}$, and $u_{0}=1$. The theoretical pressure or particle velocity along a meridian $(\phi=0)$ is chosen to compare with the complex pressure or particle velocity reconstructed from the spherical holography as shown in the following figures. The point lines present the theoretical data, and the solid lines are used to present the reconstructive data from the holographic techniques. The curves of real and imaginary pressure at 1 meter and frequency $200 \mathrm{~Hz}$ resulting from theoretical evaluation and intensity reconstruction are shown in Fig. $1 \mathrm{a}$ and $1 \mathrm{~b}$, respectively. The agreement of these lines in both figures is excellent, and the approach of determining complex pressure using one direction active in-

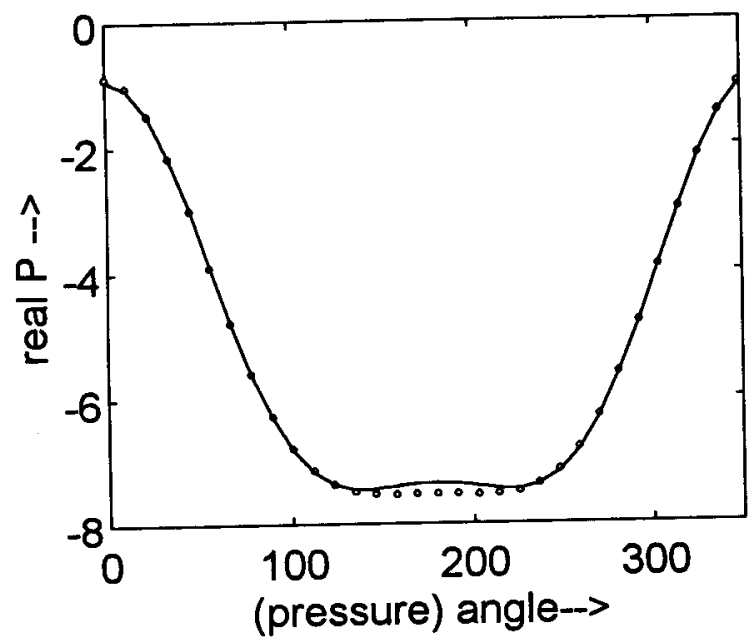

Fig. 1a. The real part of complex pressure on the hologram (with radius 0.5 meter) of meridian $(\phi=0),\left({ }^{\circ}\right.$ theoretical data, - reconstructed from intensity)

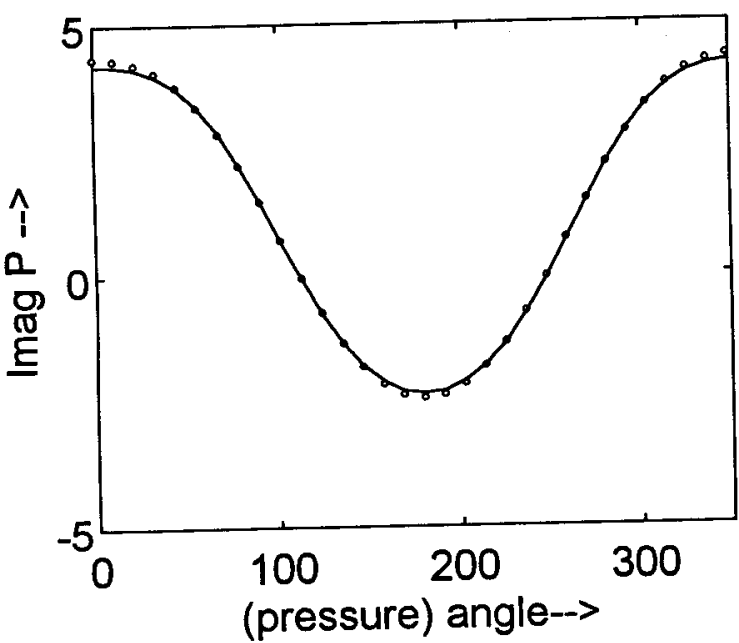

Fig. 1b. The imaginary part of complex pressure on the hologram (with radius 0.5 meter) of meridian $(\phi=0),\left({ }^{\circ}\right.$ theoretical data, reconstructed from intensity) 
tensity data for spherical acoustic holography is reliable.

The amplitude of sphere surface pressure and particle velocity reconstruct from the complex pressure on the hologram (radius 0.5 meter) at frequency $200 \mathrm{~Hz}$ are shown in Fig. 2a and 2b. Though the curves of surface velocity distribution in Fig. $2 b$ are not so agreeable as that of pressure distribution in Fig. 2a, the surface velocity distribution can be clearly investigated by using spherical holography. The surface vibration sources near $\theta=0$ can be identified. The curves in Fig. 3, with the same condition as in Fig. 2 except the reconstruction from

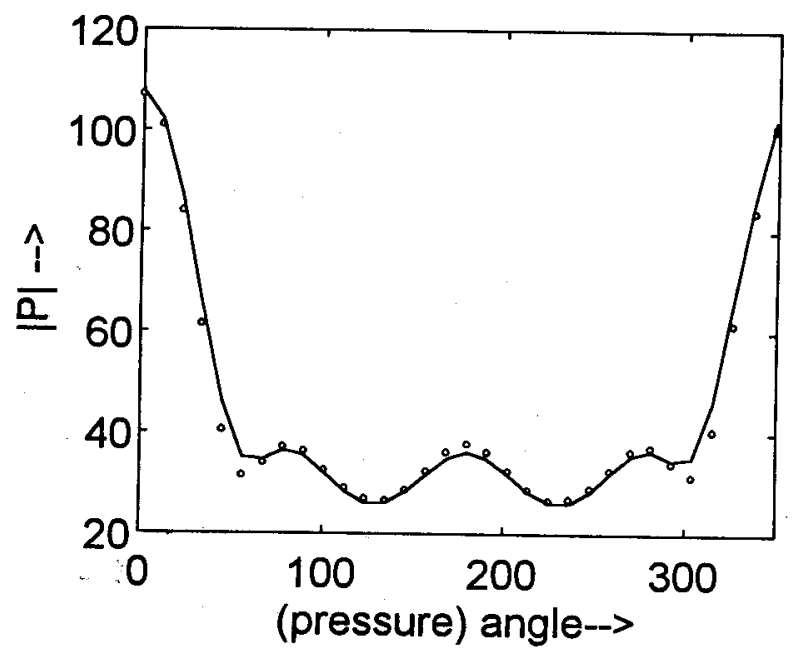

Fig. 2a. The amplitude of surface pressure reconstructed from radius 0.5 meter and for meridian $(\phi=0),\left({ }^{\circ}\right.$ theoretical data, - holographic data)

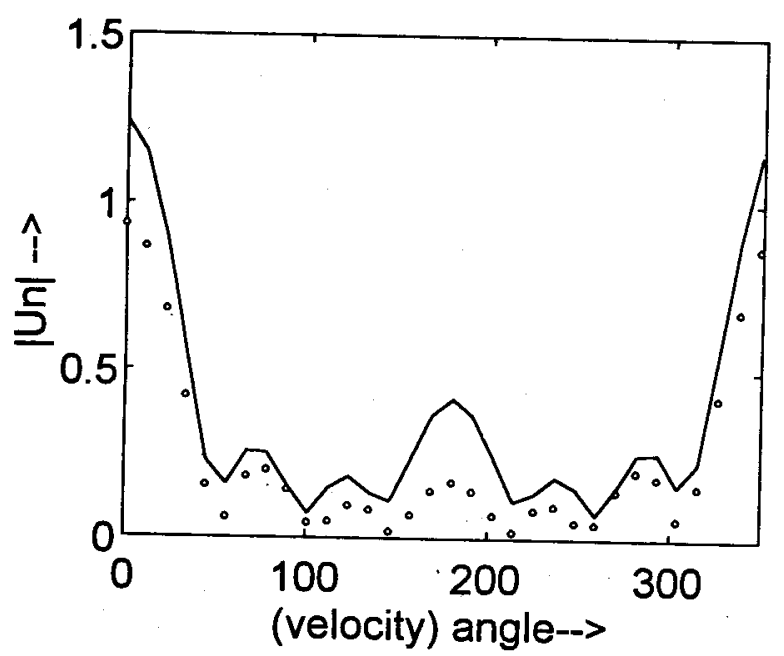

Fig. 2b. The amplitude of surface particle velocity reconstructed from radius 0.5 meter and for meridian $(\phi=0)\left({ }^{\circ}\right.$ theoretical data, holographic data) radius 1.0 meter, show that the agreement between point and solid lines is worse than that of Fig. 2. Therefore, more precise spherical acoustical holography for surface vibration identification can be obtained with the complex pressure on the hologram at a smaller radius.

\section{CONCLUSIONS}

The analysis of this study ascertained the capabilities of spherical surface vibration identification by using spherical acoustical holography. The results of numerical simulation show that the accurate com-

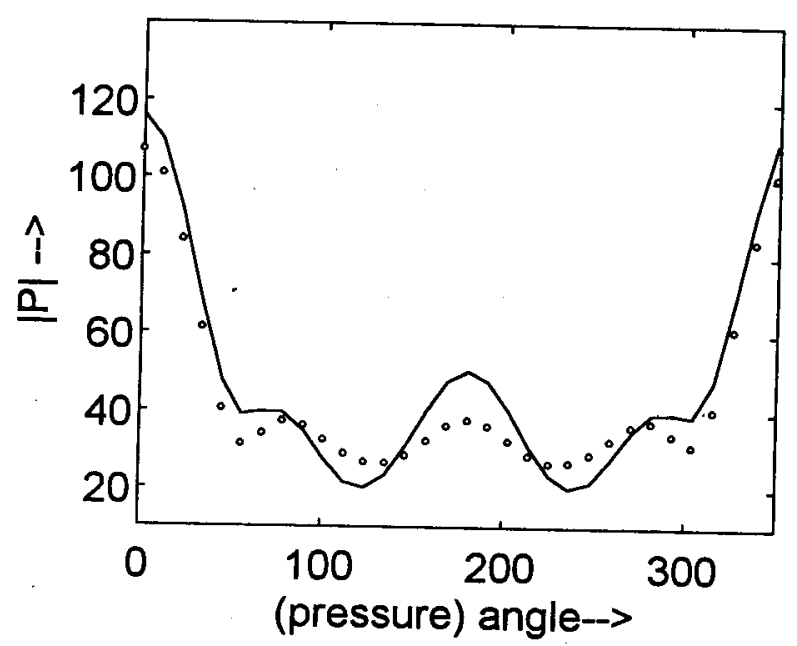

Fig. 3a. The amplitude of surface pressure reconstructed from radius 1.0 meter and formeridian $(\phi=0),\left({ }^{\circ}\right.$ theoretical data, - holographic data)

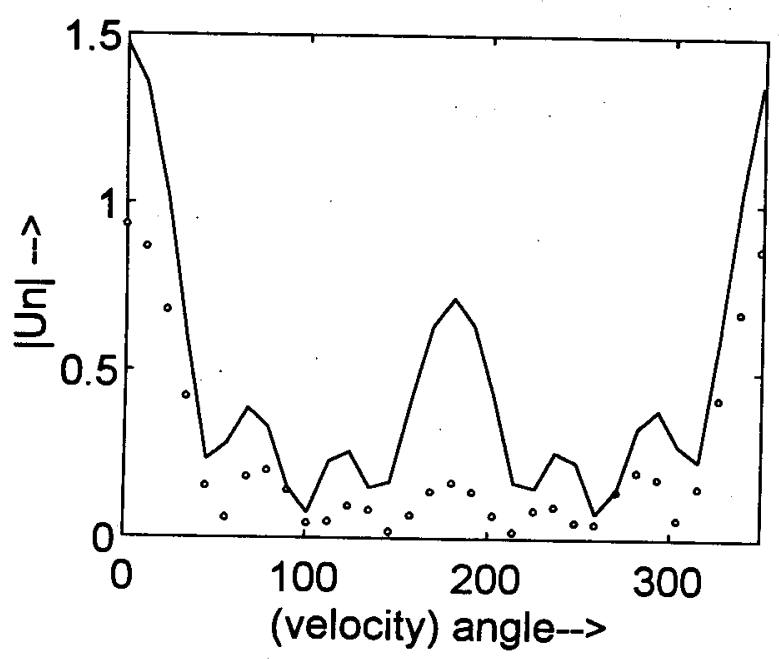

Fig. 3b. The amplitude of surface particle velocity reconstructed from radius 1.0 meter and for meridian $(\phi=0)$ ( $\left(^{\circ}\right.$ theoretical data, holographic data) 
plex pressure on the hologram can be obtained by only one direction acoustic intensity measurements. It is also shown that more accurate surface pressure and particle velocity can be reconstructed by using holographic techniques from a complex pressure on the hologram with a smaller radius. To most of small ship noise sources with random pressure signals radiation, the analysis method of this paper is applicable to identify and control the noise sources.

\section{NOTATION}

$\begin{array}{ll}A_{n m} & \text { Harmonic coefficient } \\ B_{n m} & \text { Harmonic coefficient } \\ \mathrm{F} & \text { Fourier transform } \\ F^{-1} & \text { Inverse fourier transform } \\ \mathrm{I} & \text { active intensity } \\ \mathrm{M} & \text { Spatial varible } \\ P_{n} & \text { Legendre function order } \mathrm{n} \\ \mathrm{Q} & \text { Reactive intensity } \\ Y_{n m}^{ \pm} & \text {Spherical surface harmonic } \\ h_{n} & \text { Spherical hankel function } \\ \mathrm{j} & \sqrt{-1} \\ \mathrm{p} & \text { Acoustic pressure } \\ \mathrm{u} & \text { Particle velocity } \\ \omega & \text { Angular frequency } \\ \rho_{0} & \text { Air density } \\ \nabla & \text { Gradient } \\ \theta & \text { Ploar angle } \\ \phi & \text { Azimuthal angle }\end{array}$

\section{REFERENCES}

1. Lee, J.C. "Spherical acoustical holography of low frequency noise sources," has been accepted to publish in Journal of Applied Acoustics (1996).

2. Devries, L.A., Bolton, J.S., Lee, J.C., "Acoustical holography in Spherical coordinates for noise source identification," Noise-Con 94, pp. 935-940 (1994).

3. Zhukov, A.N., Ivannikov, A.N., Pavlov, V.I., "Identification of multipole sound sources," Sov. Phys. Acoust. 36(3), pp. 249-252 (1990).

4. Weinreich, G., Arnold, E.B., "Method for measuring acoustic radiation fields," J. Acoust. Soc. Am. 68(2), pp. 404-411 (1980).

5. Laville, F., Sidki, M., Nicolas, J., "Spherical acoustical holography using sound intensity measurements: Theory and simulation," Acustic Vol. 76, pp. 193-199, (1992).

6. Williams, E.G., Houston, B.H., Bucare, B.H., "Broadband nearfield acoustical holography for vibrating cylinders," J. Acoust. Soc. Am. 86, pp. 674 (1989).

7. Loyau, T., Pascal, J.C., Gaillard, P., "Broadband acoustic holography reconstruction from acoustic intensity measurements, I: Principle of the method," J. Acoust. Soc. Am. 84, p. 1744 (1988).

8. Morse, P.M. and Ingard, K.U., Theoretical acoustics, McGraw-Hill, New York (1968).

\section{球形全相投射與聲強量測数球面振 動源之確認

$$
\text { 李仁傑 }
$$

國立台缷海洋大學输機工程技街系

$$
\text { 摘 要 }
$$

本文探討利用球形全相投射與禁強量測來確 認球面振動源之可能性。球形全相投射技術將全相 面歷反向投射，重塑出球形表面質點振動速度， 而全相面椊原分佈能由全相面繁強量测计算出。電

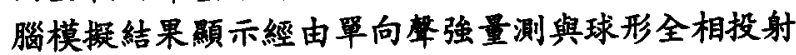
技衍能確認出球體表面振動源。 